JOURNAL

of Health Inequalities

\title{
Tobacco taxation: A key tool for public health
}

\author{
Robert Branston \\ School of Management, University of Bath, Bath, United Kingdom
}

ADDRESS FOR CORRESPONDENCE: Robert Branston, School of Management, University of Bath, BATH, BA2 7AY, United Kingdom, e-mail: J.R.Branston@bath.ac.uk

Tobacco taxes are widely regarded as one of the most effective tobacco control policies for improving the public health, which is why they are a key part of the World Health Organisation (WHO) Framework Convention for Tobacco Control (FCTC). Such taxes increase the cost of selling tobacco products, and the resulting higher retail prices provide a strong encouragement for smokers to quit their deadly habit. Tobacco taxes also provide a source of significant tax revenue, which can be used to fund other public health measures, amongst other things, and such revenues generally increase when tax rates are increased. However, recent studies have shown that the tobacco industry has adopted a range of strategies to minimise the impact of such taxes, but also that the nature of the tobacco taxes applied can help combat such actions.

Tobacco taxes are most effective when they take the form of a lump sum paid per tobacco stick, rather than when they are taxed in proportion to the sales price, and the downside of proportion taxes can be partially offset by the use of appropriate Minimum Excise Taxes. Such an approach to taxation not only reduces the pricing spread of tobacco products in the market place but also the tax in relation to the harm caused. This is important as smokers need a strong signal to quit their deadly habit, or at least to switch to less risky products if they are unwilling or unable. Tobacco taxes also need to be regularly updated in order to address the problem that tobacco products become more affordable over time as consumer incomes increase. An announced government policy commitment to regular above-inflation increases in tobacco duty is therefore helpful, although tax changes are most effective when unexpected and relatively large. If taxes are not regularly increased, research shows that the industry cleverly adjusts its prices in order to both maintain tobacco use and also increase their profits. This effectively means that the industry is increasing their profits when this money could have gone to the government in the form of higher tax revenues.

The tobacco industry often argues that tax increases will lead to large increases in illicit tobacco products that bypass tobacco taxation, but their own actions show that they do not believe this line. Recent experience in the UK also shows that tobacco taxes can be consistently increased significantly, whilst simultaneously driving down the rate of illicit tobacco use. The key is a comprehensive package of enforcement measures.

The Polish government is strongly encourage to increase taxes from their relatively low level compared to leading tobacco control countries such as the UK, Ireland, and Australia. For example, according to the European Commission as of $1^{\text {st }}$ March 2019, the taxation due on 1,000 cigarettes was only €99.45 in Poland, but $€ 329.99$ in the UK and $€ 378.49$ in Ireland. With so low levels of taxation Poland has some of the cheapest tobacco in Europe, with the Weighted Average Price of 1,000 cigarettes being just $€ 162.80$ compared to $€ 438.38$ in the UK and $€ 568.50$ in Ireland. Addressing such low levels of taxation and hence retail prices, will not only enhance the public health but will likely lead to significant increases in government tax revenue so long as there is a comprehensive enforcement strategy to combat the risk of illicit. Taxes should not only be increased significantly once but updated on a yearly basis, and also be changed to use specific taxation to the maximum extent allowed by EU tobacco rules.

Key words: tobacco, tax, public health.

\section{DISCLOSURE}

The author reports no conflict of interest. 